\title{
Advanced aerothermodynamic analysis of SHEFEX I
}

\author{
Tarik Barth*, José M.A. Longo \\ DLR Institute of Aerodynamics and Flow Technology, Lilienthalplatz 7, D-38108 Braunschweig, Germany
}

\section{A R T I C L E I N F O}

\section{Article history:}

Received 7 September 2007

Received in revised form 16 February 2010

Accepted 17 May 2010

Available online 22 May 2010

\section{Keywords:}

SHEFEX I

Re-entry

Coupled simulation

Thermodynamic effects

TAU

ANSYS

\section{Schlüsselwörter:}

SHEFEX I

Wiedereintritt

Gekoppelte Simulation

Thermodynamische Effekte

TAU

ANSYS

\begin{abstract}
A B S T R A C T
The SHarp Edge Flight EXperiment I of DLR has been established to demonstrate the feasibility of space vehicles with facetted Thermal Protection System by keeping or improving aerodynamic properties. The TPS consists of simple flat panels with sharp edges and without any constrains in the system compatibility and reliability of space vehicles. This study presents the thermodynamic behaviour of SHEFEX I during the re-entry range $28 \mathrm{~km}$ down to $19 \mathrm{~km}$ using a multidisciplinary simulation. To compare the numerical with the experimental data flow and structural calculations have been performed using the flow solver TAU and the commercial thermal solver ANSYS controlled by a loose coupling environment. Major effects like influence of sensor response time, sensor position, and sensor projection are analysed to understand the potential source of errors in numerical modelling and their impact on the results. For the selected altitude range, the calculated temperature and heat fluxes compare good with the experimental data.
\end{abstract}

(C) 2010 Elsevier Masson SAS. All rights reserved.

\section{Z U S A M M E N F A S S U N G}

Das "SHarp Edge Flight Experiment I" des DLR wurde durchgeführt, um die Machbarkeit von Raumfahrzeugen mit einem facettierten Hitzenschutzsystem unter Beibehaltung oder Verbesserung der aerodynamischen Eigenschaften zu demonstrieren. Das Hitzschutzsystem besteht aus einfachen, ebenen Paneelen mit scharfen Kanten und ohne Vorgaben in der System-Kompatibilität und Verlässlichkeit des Vehikels. Diese Studie setzt sich mit dem thermodynamischen Verhalten von SHEFEX I während des Wiedereintrittsbereiches von 28 bis $19 \mathrm{~km}$ unter Anwendung einer multidisziplinären Simulation auseinander. Um die numerischen Ergebnisse mit den experimentellen Messungen vergleichen zu können, werden Berechnungen mit dem Strömungslöser TAU und dem Strukturlöser ANSYS unter Einbindung einer losen Kopplungsumgebung durchgeführt. Wesentliche Effekte wie Einfluss der Sensor-Reaktionszeit, Sensorposition und Sensorüberstand wurden analysiert um die potentiellen Fehlerquellen der numerischen Modellierung und deren Einfluss auf die Ergebnisse aufzudecken. Für den ausgewählten Höhenbereich stimmen die Berechnungen zu den Temperaturen und Wärmestromdichten mit den experimentellen Daten gut überein.

(C) 2010 Elsevier Masson SAS. All rights reserved.

\section{Introduction}

Hypersonic systems are complex, difficult to design and expensive to build due to a lack in the physical understanding of the involved flow regimes and a lack of data for design. In order to improve the reliability of accessing space, problems related to vehicle servicing and refurbishing for instance, must be highly simplified and the time required for a design cycle has to be drastically reduced. A better understanding of the physical effects of the hypersonic flow during the reentry and their interaction with the vehicle itself is one of the key issues to improve the technology readiness level for future space systems [6]. Special attention

\footnotetext{
* Corresponding author.

E-mail address: Tarik.Barth@dlr.de (T. Barth).
}

hereby is to be paid to the thermal protection system (TPS) as this is one of the cost driving factors and as it is the most critical part during reentry. In order to meet these requirements the DLR has established the SHEFEX I program. Its goal is to measure the flow effects during a hypersonic re-entry, qualify a facetted TPS and finally demonstrate the feasibility of the sharp edge configuration for a hypersonic flight. A facetted TPS was choose, see Fig. 1, because using only a limited number of panel shapes has a realistic potential to reduce the complexity and maintains processes of a space vehicle like the Space Shuttle. Therefore the DLR decided to perform the low cost SHEFEX I experiment to study the impacts of a facetted TPS and to verify the potential of multidisciplinary design tools of the DLR.

SHEFEX I was started from northern Norway Andøya Rocket Range on 27 October'05. It flew on top of a two-stage solid propellant sounding. The project is a low cost flight experiment, which 


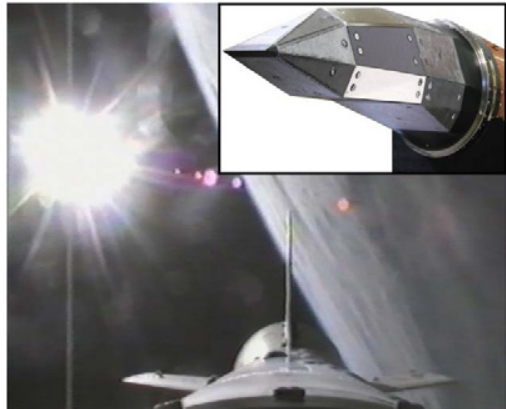

Fig. 1. The SHEFEX I forebody.

should demonstrate the feasibility of space vehicles with facetted Thermal Protection System by keeping or improving aerodynamic properties. The main purpose was to enable the time accurate investigation of the flow effects and their structural answer during the hypersonic flight from approximately $80 \mathrm{~km}$ down to an altitude of $20 \mathrm{~km}$. An additional goal of the experiment was to verify the potential of multidisciplinary design tools.

In this study the thermodynamic behaviour of the structure during the re-entry is analysed using a loose coupled fluid-thermal simulation. In order to compare the numerical with the experimental data flow and structural calculations should be performed using the flow solver TAU and the commercial thermal solver $A N-$ SYS controlled by a loose coupling environment. The goal of the present study is the understanding of the thermodynamic behaviour of SHEFEX I during the re-entry range $28 \mathrm{~km}$ down to $20 \mathrm{~km}$. Major effects like influence of sensor response time, sensor position, and sensor projection are analysed to understand the potential source of errors in numerical modelling and their impact on the results. For that a coupled analysis between the flow and structure effects and their interaction is required, because only with a complete observation of the flown re-entry experiment the flight phenomena can be captured correctly.

For the loose coupled fluid-thermal simulation the following energy balance between convection, radiation, conduction, and ablation is essential.

$\dot{q}_{\text {Conv. }}-\dot{q}_{\text {Rad.:wall } \rightarrow \text { gas }}+\dot{q}_{\text {Rad.: gas } \rightarrow \text { wall }}=\dot{q}_{\text {Cond. }}+\dot{q}_{\text {Abl. }}$

Only the term of ablation is neglected, the other components will be taken into account by the numerical calculation. However, at the beginning of the trajectory the convective heat flux is transferred near completely by conduction in the structure, because the surface temperature of the vehicle is of the order of the atmosphere temperature. Consequently, the radiation terms have no impact.

\section{Description of the experiment}

The SHEFEX I launcher is a two-stage solid propellant sounding rocket system. The launch vehicle consisted of a Brazilian S30 motor as first stage and an improved Orion motor as second stage. Between the facetted SHEFEX I experiment and the second stage were two cylindrical modules which housed the recovery system, the main electronics, the data acquisition devices, the power supply, and the cold gas system (Fig. 2).

The vehicle reached an apogee of $211 \mathrm{~km}$. The total flight time was 550 seconds, comprising 45 seconds of experimental time for the atmospheric re-entry between $90 \mathrm{~km}$ and $14 \mathrm{~km}$.

The first atmospheric effects on the acceleration sensors could be observed at $80 \mathrm{~km}$. At that level the pitch and yaw angles $(\psi$ and $\Theta$ ) started to oscillate and unfortunately the roll rate started to increase, see Fig. 3.
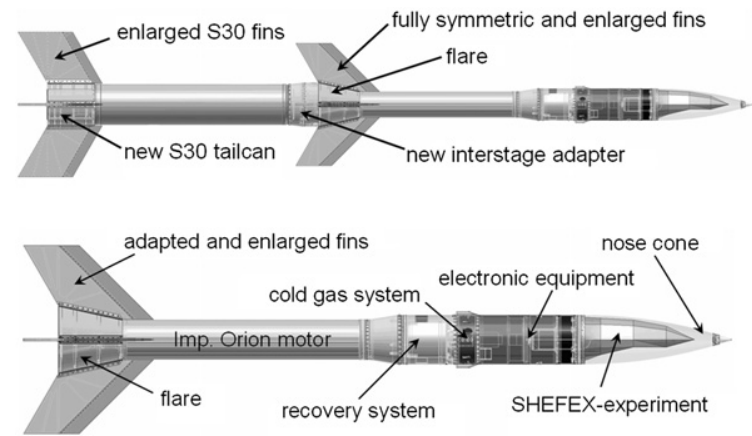

Fig. 2. SHEFEX I launcher and re-entry configuration.

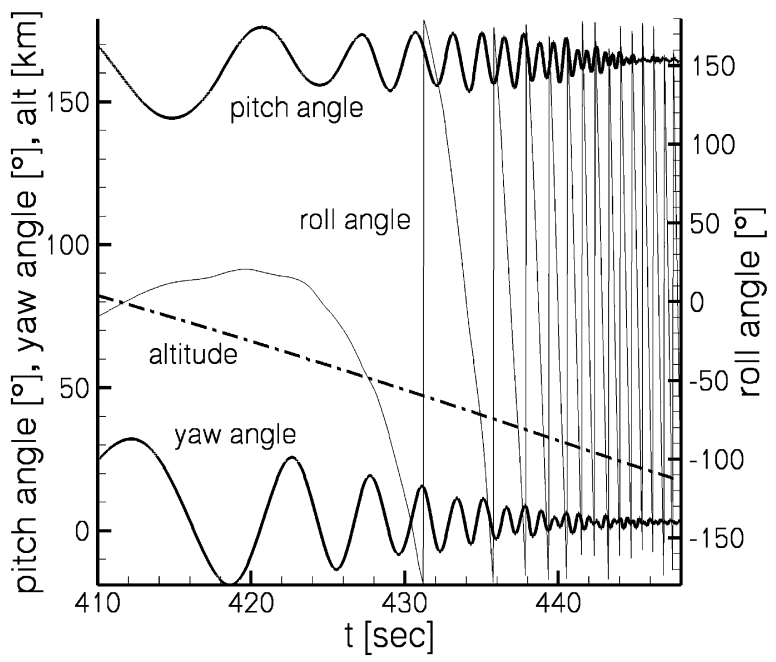

Fig. 3. Re-entry description based on DMARS data.

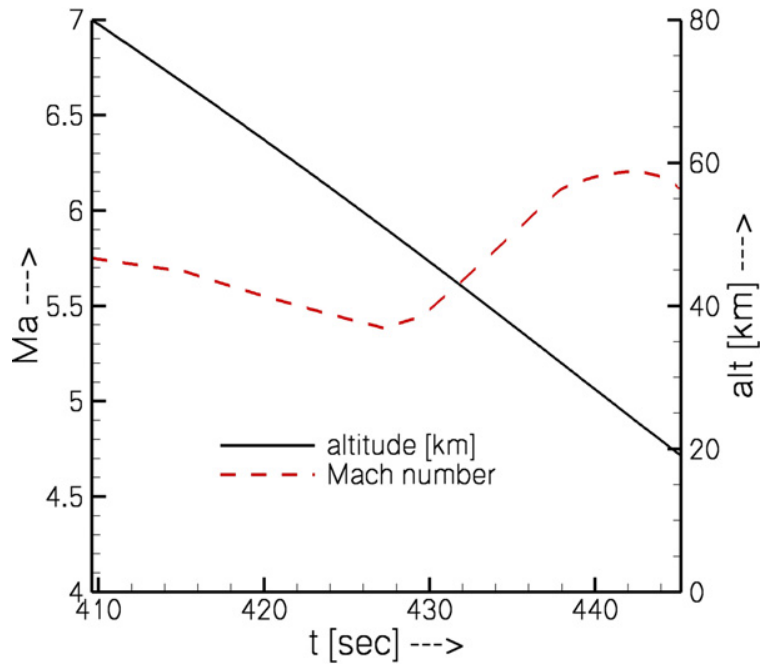

Fig. 4. Flow conditions during re-entry.

The vehicle finally achieved a stable flight attitude with a decreasing precession around the flight vector. The flight data enable a detailed flight mechanic description of the complete flight. Data of 59 sensors distributed on the surface of the forebody like pressure transducers, thermocouples, and heat flux sensors were been recorded for analysis [5].

The flight velocity during the atmospheric descent varied around $1700 \mathrm{~m} / \mathrm{s}$. The Mach number, see Fig. 4, is relatively constant, approx. 5.6 from $100 \mathrm{~km}$ down to $50 \mathrm{~km}$. Then it increases up to a maximum value 6.2 at $26 \mathrm{~km}$. 


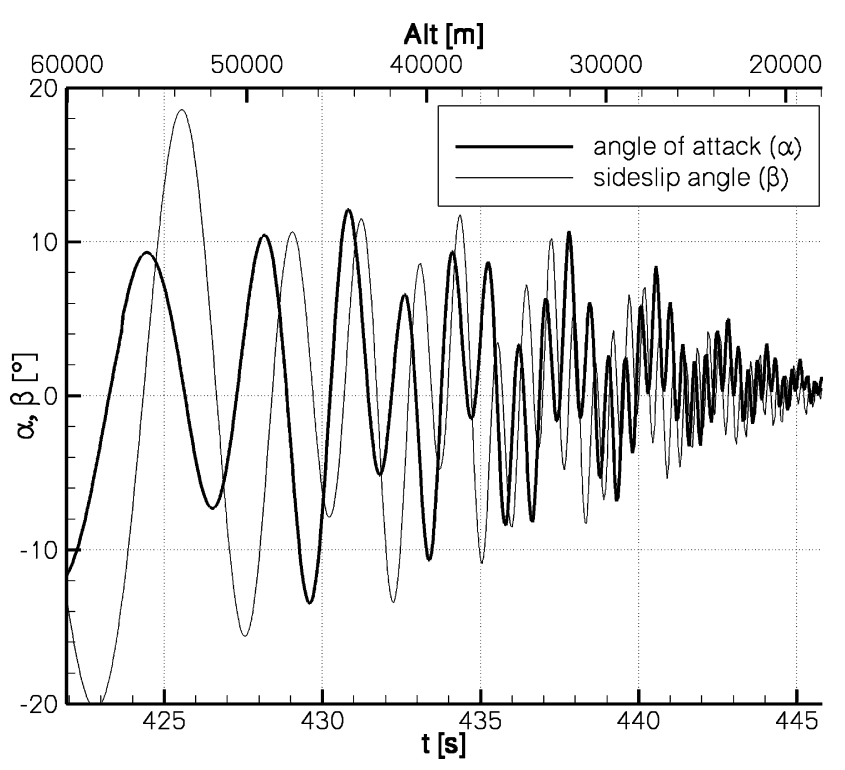

Fig. 5. Angles of attack and sideslip [1].

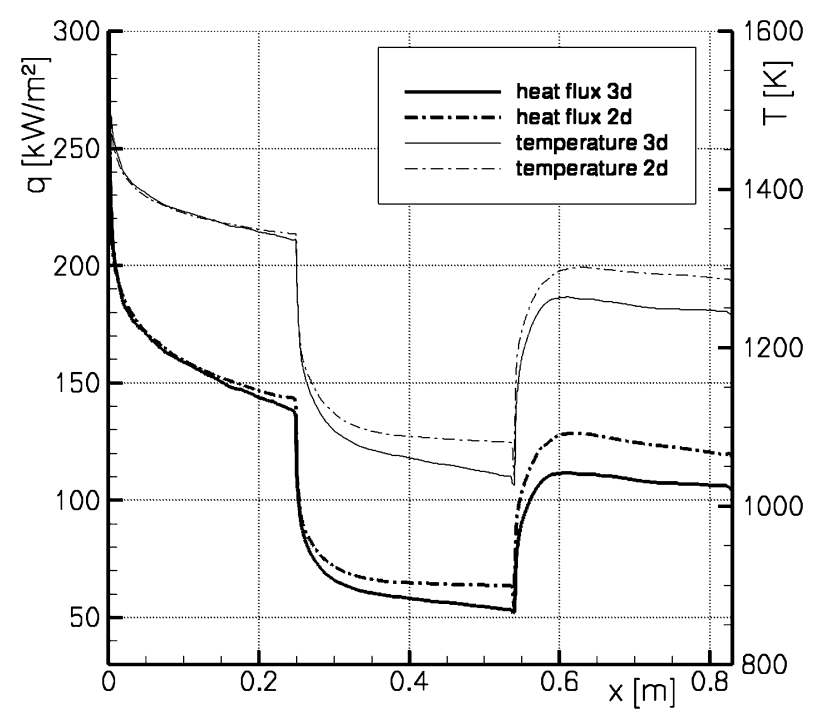

Fig. 6. Comparison of $2 \mathrm{D}$ and $3 \mathrm{D}$ calculations to heat flux and temperature of SHEFEX I [2].

For the numerical calculations and post-flight analysis the velocity vector is required. This is explicit defined by the transformed angles of attack $\alpha$ and sideslip $\beta$ which already include the effect of the roll angle $\phi$. This transformation of $\alpha$ and $\beta$ is published in [1]. Fig. 5 shows the angles of attack and sideslip which are used in the following numerical simulations.

\section{Numerical investigations}

In this section the thermodynamic behaviour of SHEFEX I during a defined altitude range of the re-entry is studied using a multidisciplinary simulation. This means that a coupled fluid-thermal calculation is applied. The numerical results are compared by experimental data.

\subsection{General comments}

In order to reduce the calculation effort a $2 \mathrm{D}$ configuration is preferred. The application of only a 2D configuration is studied in detail in a previous paper [2]. For this Fig. 6 shows a comparison of results obtained using $2 \mathrm{D}$ and $3 \mathrm{D}$ configurations.

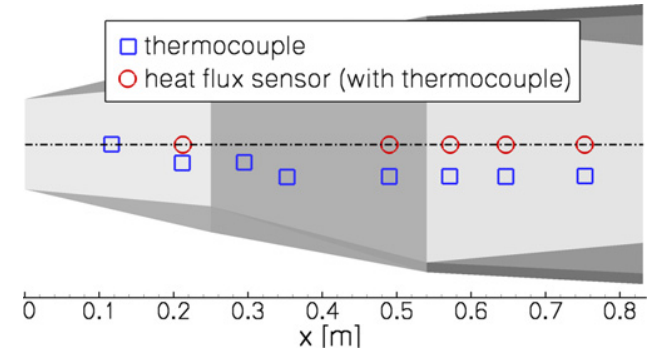

Fig. 7. Position of the heat flux sensors and thermcouples on the upper site of SHEFEX I.

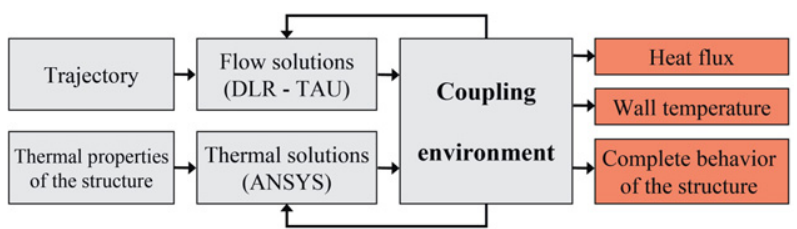

Fig. 8. Description of the coupled simulation.

The results of the comparison pointed out that the heat flux and temperature distributions are only nearly identical for 2D and 3D simulations along the first third of SHEFEX I. After that a 3D configuration has to be taken into account in order to obtain the correct results. Consequently, for the following coupled numerical calculations only a 2D configuration of the first third of SHEFEX I is analysed. Hence, the numerical results can be compared by the experimental data of a heat flux sensor (consisting of thermocouples) and a thermocouple along the symmetry line (see Fig. 7).

\subsection{Coupling environment}

The coupled simulation consists of the following four parts (see also Fig. 8):

- the flow solver DLR-TAU,

- the structural solver ANSYS,

- and the Coupling environment developed within the IMENS project,

- which uses the commercial Multi-mesh Based Code Coupling Interface $\mathbf{M p C C I}$ interpolation routine.

These parts can be explained briefly as follows [3]:

TAU is a three-dimensional parallel hybrid multigrid code for hypersonic flows. It is a finite volume scheme for solving the Euler and Reynolds-averaged Navier-Stokes (RANS) equations using tetrahedrons and prisms. Prismatic elements were used for boundary layer regions while the tetrahedral elements are used primarily in inviscid flow layer regions. A second order upwind scheme is used for the inviscid fluxes. For time discretization, including local time stepping, a three stage Runge-Kutta method is implemented. The TAU code includes different turbulence models. In the present case, the two-equation $\mathrm{k}$-w-model was used.

ANSYS is a commercial development and an analysis software which uses the Finite Element Theory. This software allows to study the physical behaviour of a structure model to a set of initial and boundary conditions applied by the user.

Coupling environment is a loose coupled approach, in which the solutions are performed using different schemes. In the present study, the CFD solver DLR-TAU calculates the surface heat flux, then its solution is interpolated using $\mathrm{MpCCI}$ and set as the boundary condition of the struc- 


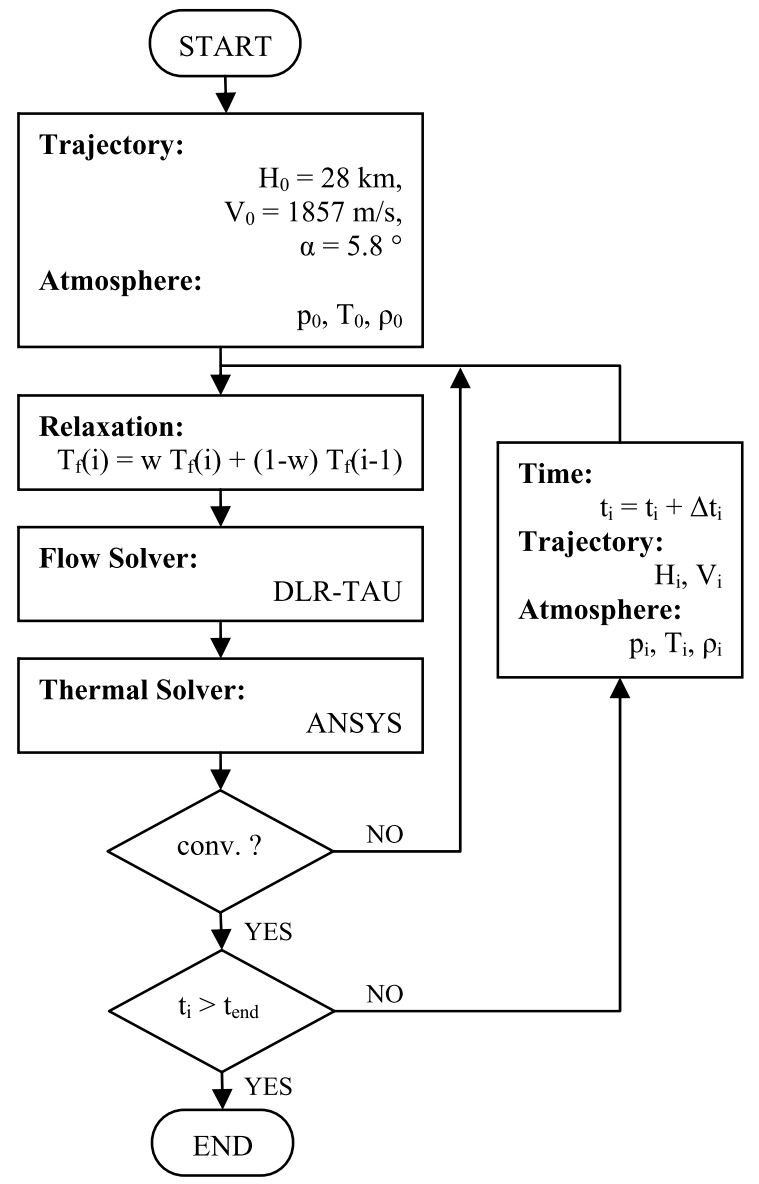

Fig. 9. Algorithm of the coupled simulation.

tural solver ANSYS. The structural solver gives the temperature associated with the applied heat flux, which is then interpolated and set as boundary condition to the flow solver. The DLR-TAU computes again the associated heat flux.

MpCCI is an interpolation routine developed by the Fraunhofer Institut, and designed to couple different simulation codes like in this case (structure and flow solvers).

In addition to these four parts, the information of the trajectory (Mach number, angle of attack and so on) and the thermal properties (conductivity, specific heat capacity and so on) of the structure are necessary as input for the simulation algorithm. Finally, the coupled fluid-thermal calculation delivers the complete thermal behaviour of the structure and description of the flow. Fig. 9 shows in detail the algorithm of the coupled simulation along the trajectory. In the first step, the initial conditions (trajectory and atmosphere) of the flow solver are defined. Then, the iterative calculation of the fluid-thermal problem for each time step is carried out.

Hence, the following convergence criterion is defined for each time step:

$\varepsilon=\frac{\left|T_{f}(i)-T_{f}(i-1)\right|^{2}}{\left|T_{f}(i-1)\right|^{2}}$

where $T_{f}$ is the fluid temperature on the wall. If the convergence criterion is achieved (for instance $\varepsilon \leqslant 0.001$ ), the next time step (iteration) can be computed. However, the flight condition, mainly the angle of attack and the atmosphere values, are change in each time step. Consequently, every time step required a distinct cal-

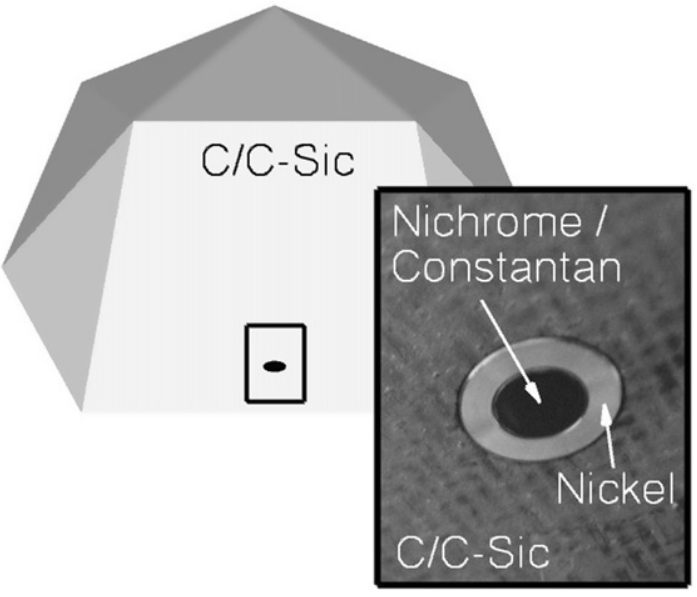

Fig. 10. Material composition of SHEFEX I.

culation effort in order to achieve a converged solution. The relaxation is usefully for steady cases in order to obtain a smooth convergence. In case of unsteady solutions, the relaxation factor may be set to near value of 1 and the time step should be chosen small enough. In this study, the flow is solved steadily and the thermal behaviour of the structure unsteadily, because the ratio between the characteristic time of the thermal conduction and the fluid dynamic is small [7], of the order of $10^{-6}$. This ratio is given as follows

$\frac{t_{\text {Fluid }}}{t_{\text {Structure }}}=\frac{k}{R_{n} \cdot V}$

with

$k=\frac{\lambda}{\rho \cdot C}$

Here, $k$ is the thermal diffusivity of the material, $R_{n}$ the curvature radius, $V$ the velocity, $\lambda$ the thermal conductivity, $\rho$ the density, and $C$ the heat capacity.

\subsection{Structure model}

Fig. 10 shows the materials of SHEFEX I-TPS and that of the included heat flux sensor of the first third of the vehicle which is (2D) investigated.

The TPS, with a thickness of $3 \mathrm{~mm}$, consists of the DLR's Carbon Reinforced Silicon Carbide (C/C-SiC) material, which has demonstrated very moderate erosion behaviour at extreme heat loads in the past [4]. On the other hand the heat flux sensor consists of a combination of Nickel (housing) and Nichrome/Constantan (thermopile). Because of that the thermal properties of the TPS and the sensor are different. Therefore, both materials will be heated-up at different speed and their wall temperatures have to be considered separately for the thermal model.

The inside of the vehicle is isolated by an aluminium oxide $\left(\mathrm{Al}_{2} \mathrm{O}_{3}\right)$ fibre with a thickness of $27 \mathrm{~mm}$. The complete thermal model is shown in Fig. 11.

\subsection{Mesh sensitivity analysis}

In this subsection, the influence of the structure mesh is valued on the basis of three grids of different sizes. Especially the mesh discretization within the TPS has been investigated. The selected grids are summarized in Table 1.

The number of elements in normal direction of the TPS increases for each refinement on the order of one element and begins with two elements (coarse grid). 


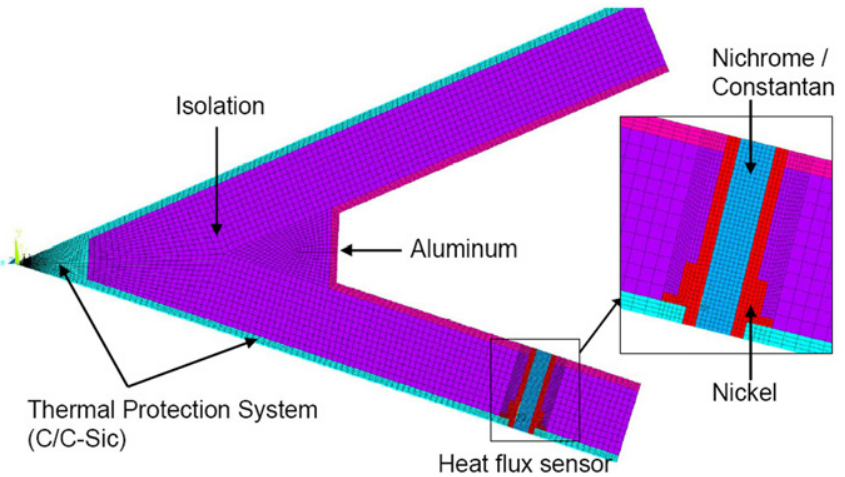

Fig. 11. Analysed thermal model of the $2 \mathrm{D}$ configuration.

Table 1

Description of the structural grids.

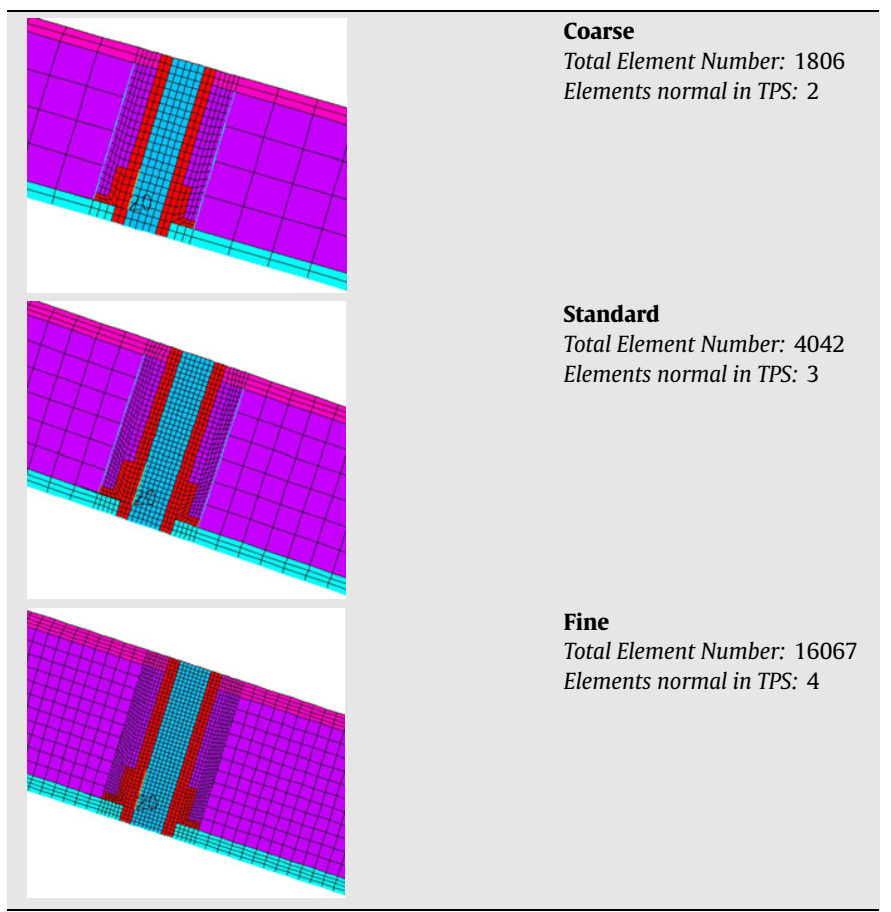

In Fig. 12 the results (temperature and heat flux distribution on the lower surface) of the mesh sensitivity study are shown. For these calculations a steady coupled algorithm is applied. Because of the different thermal properties of the TPS and the heat flux sensor, the illustrated wall temperature and heat flux distributions reflect the different heating-up of both materials. The results of the calculations pointed out that the differences between the investigated meshes are mainly on the order of 1-2 percents. Only the coarse grid delivers a clear deviation in near of the leading edge $(x \approx 0)$.

Nevertheless, it can be summarized that the application of the coarse grid is recommended for a global thermal analysis of SHEFEX I in order to save the calculation effort. In case of a detailed analysis of the leading section of SHEFEX I, at least a standard mesh should be applied.

The discretization of the leading edge is studied in detail in following. During the re-entry flight a changing of the geometry as a result of high temperature (ablation) would be accepted. Also an absolute sharp edge is with respect to manufacture tolerances not possible. Wherefore, a radius of the leading edge of $R=0.1 \mathrm{~mm}$ is assumed. In this context it can be added that the results are nearly

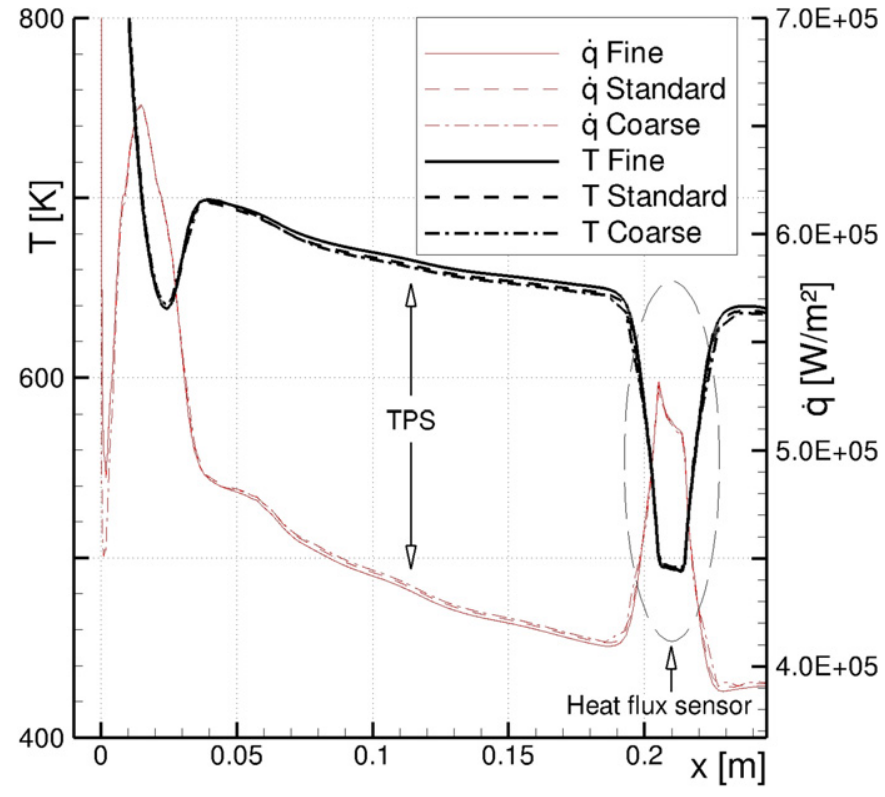

Fig. 12. Temperature and heat flux distribution on the lower surface of the mesh sensitivity study. Steady coupled simulation for $M=6.2$, Alt $=24 \mathrm{~km}$, and $\alpha=2.5^{\circ}$.

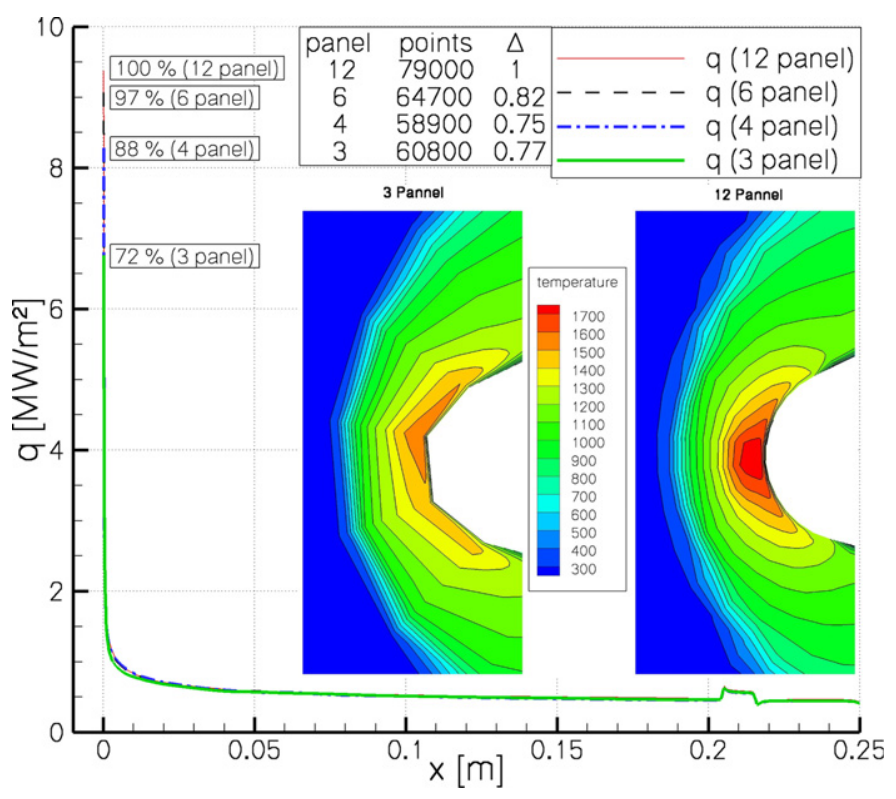

Fig. 13. Computed temperature and heat flux distribution using different discretization levels $(3,4,6$, and 12 panels $)$ for the leading edge $(M=6.2$, Alt $=24 \mathrm{~km}$, and $\alpha=0^{\circ}$ ).

equal within the radius range $0.02-2 \mathrm{~mm}$ [1]. The discretization of the leading edge is investigated on the basis of four different levels (3, 4, 6, and 12 panels). The first case with 3 panels allows only a very coarse reproduction of the curve. In opposite to that, the curve is portrayed exactly using 12 panels. The results of this comparison are shown in Fig. 13. At first it can be noted that the heat flux at the leading edge is only computed correctly when at least 6 panels are used. In case of less than 6 panels, the heat flux at the leading edge is too small. The best result is obtained using 12 panels. However, the discretization of the leading edge with 6 panels saves in comparison to 12 panels $18 \%$ of the mesh points with reasonable accuracy. Consequently, in the following calculations the leading edge will be discretized using 6 panels. 
Table 2

Response time of the heat flux sensor and mantle thermocouple (manufacturer information).

\begin{tabular}{ll}
\hline Sensor & Response time \\
\hline $\begin{array}{l}\text { Heat flux microsensor } \\
\quad \text { (thermocouple cascade) }\end{array}$ & $t=0.3 \mathrm{~ms}$ \\
Mantle thermocouple & $t=0.3 \mathrm{~s}$ (in water with $0.4 \mathrm{~m} / \mathrm{s}$ ) \\
NiCr-Ni type " $K$ " & $t=8.0 \mathrm{~s}$ (in air with $2.0 \mathrm{~m} / \mathrm{s}$ ) \\
\hline
\end{tabular}

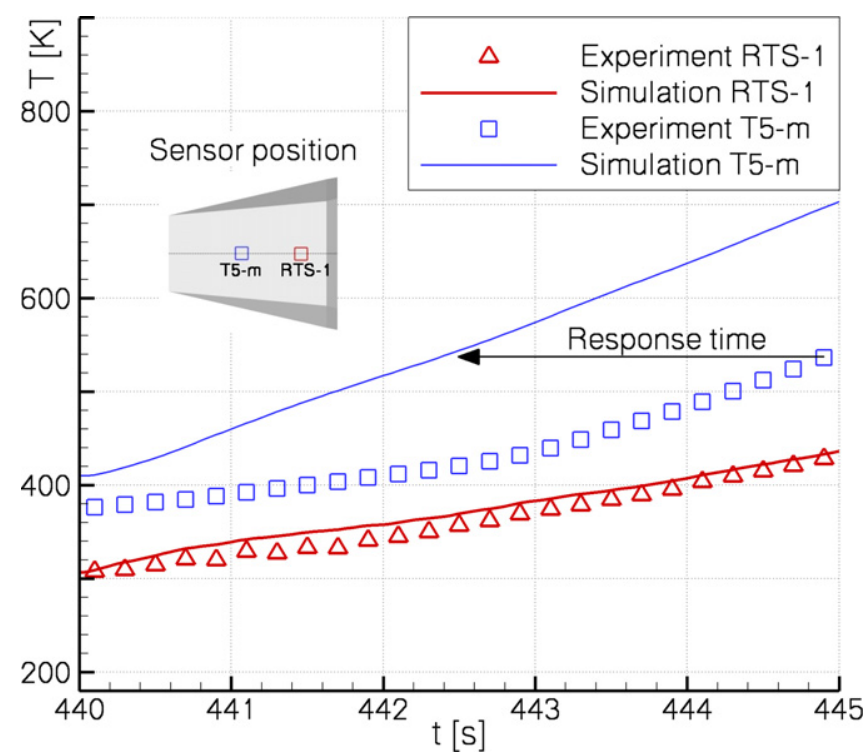

Fig. 14. Comparison of numerical and experimental temperature distribution during the re-entry $(28-19 \mathrm{~km})$.

\subsection{Numerical results of the re-entry}

In this subsection comparisons of numerical and experimental data of the re-entry within the altitude range of $28 \mathrm{~km}\left(t_{\text {re-entry }}=\right.$ $440 \mathrm{~s})$ down to $19 \mathrm{~km}\left(t_{\text {re-entry }}=445 \mathrm{~s}\right)$ are carried out. The investigated re-entry flight comprises 5 seconds represented with 100 time steps $(\Delta t=0.05 \mathrm{~s})$. A previous study shows that the boundary layer has to be defined as turbulent within this altitude range [1].

In order to interpret correctly the comparison of the experimental and numerical data, Table 2 shows the response times of the heat flux sensor and mantle thermocouple according to the manufacturer information.

The heat flux sensor consists of a thermocouple cascade with very fast response behaviour ( $t=0.3 \mathrm{~ms}$ ). In opposite to that, the mantle thermocouple has a distinct response time $(t=0.3-8.0 \mathrm{~s})$. The problem is that the manufacturer identifies two different response times measured in air and water respectively. However, the response time of the thermocouple included in the TPS (ceramic material) is unknown and has to be measured in future experiments. This problem is reflected in the results of the coupled numerical calculations, summarized in Fig. 14.

Here, the experimental temperature distribution of the mantle thermocouple $T 5-m$ inside of the TPS differs from the numerical results assumedly as a result of the response time. This will be confirmed by the fact that the gradients of the experimental and numerical temperatures are nearly equal. On the basis of these results, the response time of the mantle thermocouple may be estimated to approximately 2.5 seconds. This value corresponds with the given manufacture information.

The numerical results of the surface temperature on the heat flux sensor (RTS-1) are nearly equal to the measurement, because of the very fast response behaviour of the senor. Both gradients
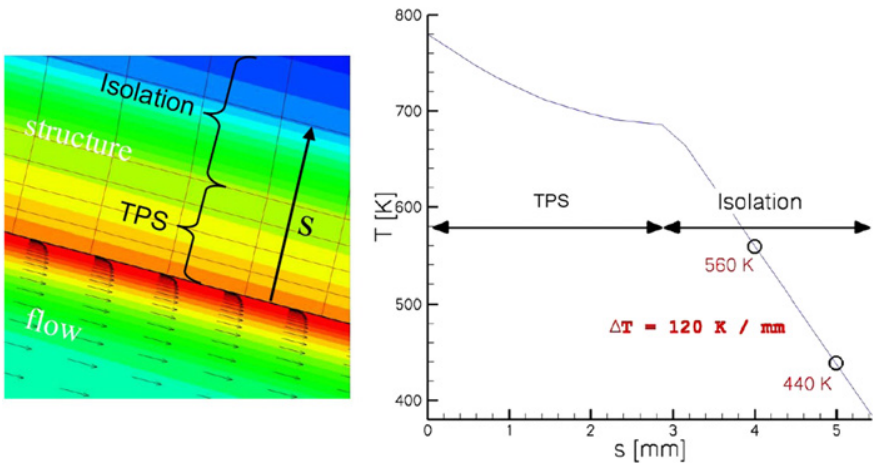

Fig. 15. Temperature distribution of the fluid and structure, $t=445 \mathrm{~s}$, position: T5-m.
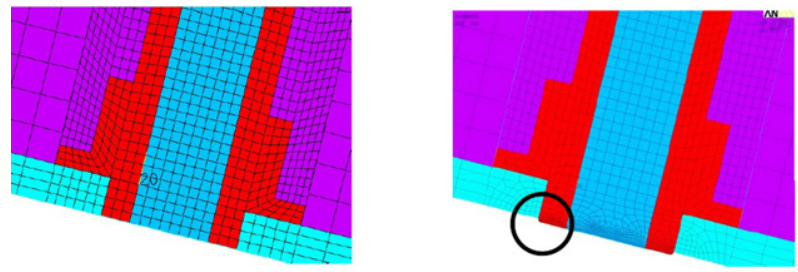

without projection

with projection

$0.25 \mathrm{~mm}$

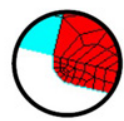

Fig. 16. Mounting conditions of the heat flux sensor.

and quantities of the temperature can be recalculated correctly using the coupled fluid-thermal simulation.

In addition to the mentioned response time it is investigated whether the thermocouple position within the structure is an important parameter and source of error during the analysis. For this, Fig. 15 shows the distribution of the temperature within the TPS and isolation along the plotted line.

The results pointed out that the respective sensor position affects enormously the temperature measurement. For instance, within the isolation a changing of the thermocouple position on the order of only $1 \mathrm{~mm}$ causes a temperature variation of $120 \mathrm{~K}$ $(\Delta T=120 \mathrm{~K} / \mathrm{mm})$.

Finally, the heat flux distribution is analysed on the basis of two different cases with respect to the mounting condition of the senor. For case $I$, the heat flux sensor has no projection, i.e. it is flash mounted with respect to the vehicle outer model line. In case II, it is assumed that the sensor has a projection of $0.25 \mathrm{~mm}$ outside the outer model line, see Fig. 16.

The case with projection is more properly, because the installation condition of the heat flux sensors within the TPS was not absolutely smooth, see Fig. 10 .

The experimental and numerical data of the investigated reentry range are presented in Fig. 17. First of all, it has to be noted that the measurement of the HFS-1 heat flux sensor (red curve) is trustable until $t=444 \mathrm{~s}$. After this, the experimental values are faulty, because their upper peaks are not measured. The rest of the heat flux distribution reflects correctly the change of the angle of attack, because the curve oscillates accordingly.

For the numerical simulation a turbulent boundary layer is assumed. However, the measurement shows that between $t=440 \mathrm{~s}$ to $442 \mathrm{~s}$ the state of the boundary layer is changing between laminar and turbulent depending on the angle of attack. Consequently, here transition effects are present. That is the reason of the higher amplitudes of the flight data. After $t=442 \mathrm{~s}$ a full turbulent boundary layer is following and the amplitude of the 


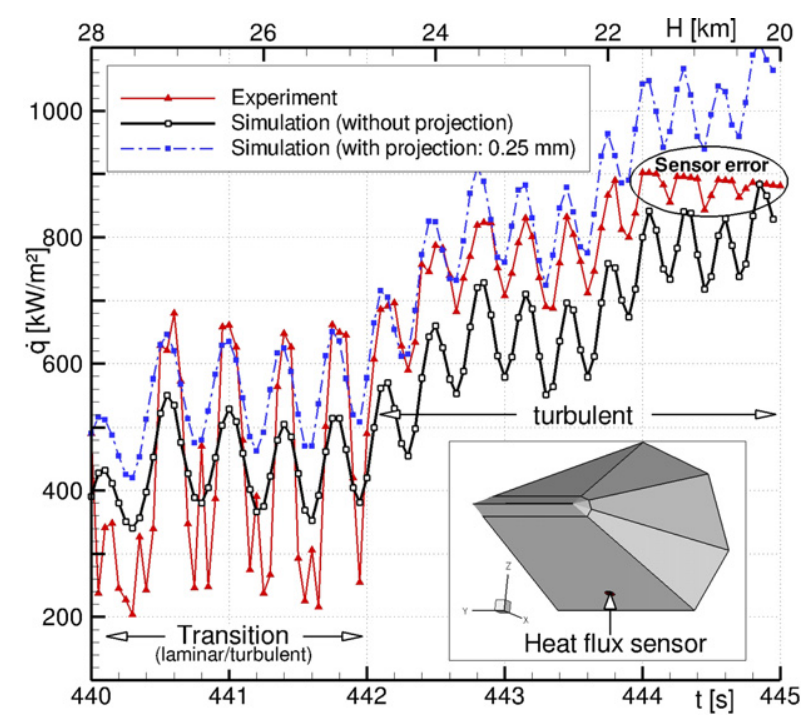

Fig. 17. Comparison of numerical and experimental heat flux distribution during 28$19 \mathrm{~km}$ without/with sensor projection. (For interpretation of the references to color in this figure, the reader is referred to the web version of this article.)

oscillation of flight data is reducing. The simulation without projection (case $I$ ) delivers the heat flux plotted by the black curve. In this case the results are similar to the measurement. Particularly the gradients portrayed are satisfied by the coupled simulation. From $t=442 \mathrm{~s}$ the computed values are below the experiment. In case with projection (blue dot-line-curve) the qualitative run of the curve is equal to the case without projection. However, the heat flux has a distinct offset. Therefore, the projection length of the heat flux sensor is an important parameter which has to be taken into account during the analysis, because a small projection on the order of only $0.25 \mathrm{~mm}$ causes an increasing of the heat flux about $100-200 \mathrm{~kW} / \mathrm{m}^{2}$.

\section{Conclusions}

In this study an advanced aerothermodynamic analysis to SHEFEX I has been performed. Carefully investigations to the influence of sensor response time, sensor position, and sensor projection are carried out using a coupled fluid-thermal calculation within the re-entry range $28 \mathrm{~km}$ down to $19 \mathrm{~km}$. It can be summarized that the response time of the mantle thermocouple plays a very important rule for the post-flight analysis and has to be measured in future experiments. On the basis of numerical results, the response time of the mantle thermocouple may be estimated to approximately 2.5 seconds. Besides the analysis shows that sensor position within the TPS affects enormously the temperature measurement. A small change of the position causes a distinct temperature variation. The heat flux distribution is analysed on the basis of two different cases with respect to the mounting condition of the senor (with and without projection). The results pointed out that the projection length of the heat flux sensor is an important parameter which has to be taken into account during the analysis.

Considering all investigated sources of errors the numerical results for the temperature and heat flux distributions of the analysed re-entry range offer a good agreement in comparison with experimental data.

\section{Acknowledgement}

The authors would like to thank J. Bartolomé Calvo for this help and support in context with this work.

\section{References}

[1] Tarik Barth, Eggers Thino, SHEFEX - A first aerodynamic post-flight analysis, in: 15. DGLR-Fach-Symposium AG STAB, Darmstadt (de), 2007.

[2] Tarik Barth, Aero- and thermodynamic analysis to SHEFEX I, Engineering Applications of Computational Fluid Mechanics 1 (1) (2007).

[3] J. Calvo Bartolomé, A. Mack, O. Bozic, Study of the heating of a hypersonic projectile through a multidisciplinary simulation, in: ECCOMAS CFD 2006, Delft, Netherlands.

[4] Th. Eggers, J.M.A. Longo, J. Turner, W. Jung, M. Hörschgen, A. Stamminger, A. Gülhan, F. Siebe, G. Requardt, T. Laux, T. Reimer, H. Weihs, The SHEFEX flight experiment - Pathfinder experiment for a sky based test facility, AIAA Paper 2006-7921, 2006.

[5] A. Gülhan, G. Requardt, F. Siebe, U. Koch, B. Esser, Instrumentation and in-flight data of the SHEFEX flight experiment, in: Proceedings of the 1st International ARA Days on Atmospheric Re-Entry Systems, Missions and Vehicles, Arcachon, France, June 2006.

[6] I.A. Johnston, M. Weiland, J. Martinez-Schramm, K. Hannemann, J.M.A. Longo, Aerothermodynamics of the ARD: Post-flight numerics and shock-tunnel experiments, AIAA Paper 2002-0407, 2002.

[7] R. Savino, M.D.S. Fumo, D. Paterna, M. Serpico, Aerothermodynamic study of UHTC-based thermal protection systems, Aerospace Science and Technology 9 (2005) 151-160. 